\title{
GESTÃO ESCOLAR: A OPINIÃO DOS PROFISSIONAIS DE EDUCAÇÃO SOBRE O SISTEMA DE TECNOLOGIA EDUCACIONAL DO ESTADO DO RIO DE JANEIRO1
}

\author{
http://dx.doi.org/10.5902/2176217114875
}

\author{
Lucia Helena Esteves Pereira \\ Universidade Federal Fluminense, Brasil.
}

Isabel Cabral

Universidade Federal Fluminense, Brasil.

\begin{abstract}
Resumo
O objetivo deste trabalho foi identificar a opinião dos usuários da tecnologia educacional, para gestão escolar, utilizada na rede estadual de ensino no estado do Rio de Janeiro. Um questionário, com onze perguntas, foi aplicado aos profissionais que fazem parte da equipe administrativa, pedagógica, além dos professores de uma instituição de ensino estadual, localizado na cidade de Volta Redonda/RJ, no período de 4 a 22 de novembro de 2013, nos turnos da manhã e noite. Foram 40 respondentes, sendo a maioria composta de professores atuantes em sala de aula. $O$ resultado mostrou que, para alguns profissionais pesquisados, a ferramenta utilizada pelas escolas públicas do Estado é inovadora e útil, mas ainda está longe de contemplar todas as necessidades da educação. Também foi apurado que o sistema de gestão apresenta pontos fortes e pontos fracos, cabendo a todos os atores do universo escolar a obrigação de reforçar os pontos fortes e reduzir os pontos fracos em busca da melhoria da qualidade na educação no Estado do Rio de Janeiro.

Palavras-chave: educação, tecnologia, gestão.
\end{abstract}

\section{SCHOOL MANAGEMENT: THE VIEWS OF EDUCATION PROFESSIONALS ON THE SYSTEM OF EDUCATIONAL TECHNOLOGY IN THE STATE OF RIO DE JANEIRO}

\begin{abstract}
The objective of this study was to identify the views of users of educational technology for school management, used in state schools in the state of Rio de Janeiro. A survey with eleven questions was applied to the professionals who are part of the administrative, pedagogical staff, in addition to teachers from a state education institution located in the city of Volta Redonda/RJ for the period 4 at to 22 november 2013 in the morning and evening. Were 40 respondents, mostly composed of teachers working in the classroom. The result showed that for some professionals surveyed, the tool used by public schools in the state is innovative and useful, but it is far to cover all the needs of education. Also, it was found that the management system has strengths and weaknesses,
\end{abstract}

1 Artigo baseado na monografia apresentada ao Curso de Administração Pública, modalidade semipresencial, do Instituto de Ciências Humanas e Sociais da Universidade Federal Fluminense.

\begin{tabular}{|l|l|l|l|l|l|l} 
Regae: Rev. Gest. Aval. Educ. & Santa Maria & v. 4 & n. 7 & Jan./jun. 2015 & p. 47-60
\end{tabular}


being all the actors in the school universe the obligation to enhance the strengths and reduce the weaknesses in the pursuit of quality improvement in education in the state of Rio de Janeiro. Key-words: education, technology, management. 


\section{Introdução}

s organizações públicas, ao longo dos anos, passaram por vários processos $\triangle$ de modernização em sua estrutura administrativa. Vários setores públicos dos serviços.

A escola pública também passou por várias mudanças, tanto para se adaptar à legislação, quanto para buscar melhoria da qualidade. A gestão escolar se modernizou, tornando-se mais democrática, participativa e dinâmica. A tecnologia chegou à escola pela informatização de vários setores, dos laboratórios de informática e do uso de computadores pelos alunos na realização das atividades escolares, tanto nas escolas, quanto em suas casas.

A gestão escolar ganhou ares empresariais ao incorporar técnicas de gestão modernas e novas tecnologias utilizadas nas empresas para melhor aplicação dos recursos públicos e melhor atendimento à comunidade escolar, como: programas para realizar prestações de contas das verbas recebidas, sistemas de gerenciamento para lidar com os documentos da secretaria, dos professores, montagem de quadros de horários etc. A tecnologia passou a ser uma das ferramentas necessárias no processo decisório da gestão escolar.

Diante desses fatos surgiu a necessidade de se verificar a opinião dos profissionais de educação. A intenção de se utilizar a tecnologia como meio para a inovação da gestão escolar é uma forma de lançar mão de ferramentas que contribuam para o melhor aproveitamento de todos os benefícios que a tecnologia pode oferecer. Não basta ter laboratórios de informática nas escolas, é preciso que a equipe escolar busque inovar sempre, é fazer com que ela seja parte do conteúdo programático e utilizá-la para a formação integral dos nossos alunos. É preciso criar diferentes oportunidades de contato com a tecnologia, não se limitando ao uso esporádico do laboratório de informática ou de ferramentas de projeção. A tecnologia deve estar presente em todos os setores da escola.

São diversas as situações que envolvem uma unidade escolar. Além do aspecto educacional, pedagógico, que é a razão de existir de toda unidade escolar, muitas variáveis estão envolvidas nessa questão: o gerenciamento de verbas para a manutenção, gestão de pessoas, organização e cumprimento de horários, aspectos sociais, aspectos pedagógicos e a tecnologia utilizada para a gestão, dentre outras.

O governo do Estado do Rio de Janeiro vem, desde 2009, implantando um sistema tecnológico de gestão escolar, o Conexão Educação, que integra três áreas: administrativa, docente e discente. Desta forma surgiu a seguinte questão: qual a opinião dos profissionais de educação quanto ao uso da tecnologia educacional, Conexão Educação? Diante da quantidade de usuários do sistema optou-se por restringir a pesquisa aos profissionais de educação.

O objetivo deste trabalho foi identificar a opinião dos usuários da tecnologia educacional para gestão escolar utilizada na rede estadual de ensino no Estado do Rio de Janeiro.

\section{Principais políticas públicas de educação do Estado do Rio de Janeiro}

De acordo com a Lei de Diretrizes e Bases da Educação nacional a educação básica é formada pela educação infantil, ensino fundamental e ensino médio (art. 21, inciso I). 
Para atender ao inciso III do artigo 10 da LDBEN, os Estados devem elaborar e executar "políticas e planos educacionais, em consonância com as diretrizes e planos nacionais de educação, integrando e coordenando as suas ações e as dos seus Municípios."

Como parte das políticas públicas de educação, o governador do Estado do Rio de Janeiro sancionou a lei n. 5.597, de 18 de dezembro de 2009, que aprovou o Plano Estadual de Educação. Trata-se de um instrumento elaborado com objetivos e metas para as três etapas que compõem a educação básica. A lei determina, também, que a revisão do plano seja feita a cada dois anos, após a realização do Congresso Estadual de Educação.

O Plano Estadual de Educação do Estado do Rio de Janeiro esclarece que os objetivos e metas "estão direcionados para a ampliação e universalização do ensino com a qualidade que permita a continuidade de estudos para àqueles que optarem pela educação superior" (2009, p. 29).

Dentre os objetivos e metas estabelecidos para a educação básica no Estado do Rio de Janeiro, cabe destacar os seguintes itens:

6. Implantar, no prazo de 10 (dez) anos, a partir da publicação deste Plano, o tempo integral no Ensino Médio, em 10\% das escolas da rede pública estadual, priorizando áreas com jovens em situação de risco, sem prejuízo do atendimento à demanda e considerando a necessidade de ampliação do número de unidades escolares. 7. Assegurar na rede pública estadual, no prazo de 5 (cinco) anos, a partir da publicação deste Plano, preferencialmente por meio de concurso público, o preenchimento de $100 \%$ de vagas do Quadro de Profissionais da Educação, observando-se os requisitos necessários para o exercício de cada função, a fim de garantir padrões de qualidade para os ensinos Fundamental e Médio. 11. Elaborar e implantar, no prazo de 5 (cinco) anos, a partir da publicação deste Plano, políticas públicas para regularização do fluxo escolar, objetivando reduzir em $10 \%$ ao ano, as taxas de repetência e de evasão, por meio de programas que possibilitem a efetiva aprendizagem do aluno, respeitando as condições necessárias para que isso se dê com qualidade. 25. Garantir, a partir da publicação deste Plano, a continuidade do Sistema de Avaliação da Educação do Estado do Rio de Janeiro (Saerj), possibilitando a realização de avaliações do sistema de ensino estadual e o estabelecimento de metas de desempenho para alunos do $5^{\circ}$ ano do Ensino Fundamental, até - $3^{\circ}$ ano do Ensino Médio. 26. Estimular, a partir da publicação deste Plano, que as escolas darede estadual definam objetivos e metas próprias anuais - que tenham por base diagnósticos realizados, a partir da utilização de dados estatísticos do Sistema de Avaliação da Educação do Estado do Rio de Janeiro (Saerj), tais como número de matrículas,taxas de distorção idade-série, frequência e rendimento escolar -, que as auxiliem a acompanhar o desempenho dos indicadores educacionais associados à sua realidade específica, contribuindo para o avanço da qualidade da sua educação. 31. Apoiar e viabilizar, no prazo de 1 (um) ano, a partir da aprovação deste Plano, a promoção pela Secretaria de Estado de Educação de encontros de professores das unidades escolares, objetivando reflexões sobre a escola, sua finalidade, seus problemas e possíveis propostas para a melhoria da Educação Básica, cujas datas deverão estar incluídas no calendário letivo. 36. Equipar, no prazo de 2 (dois) anos, a partir da publicação deste Plano, e manter todas as escolas de Ensino Fundamental e Médio da rede pública estadual 
de ensino com computadores, conexões com a Internet em alta velocidade, fax, telefonia, que possibilitem a ampliação da Rede Regional de Tecnologia Educacional (RTE) e que atendam inclusive aos alunos com deficiências. 37. Promover a inclusão tecnológica e o retorno imediato, a partir da publicação deste Plano, da função dos orientadores tecnológicos, em como ampliar o quadro, para atender aos alunos e professores capacitando-os em tecnologias educacionais. (Lei n. 5.597/2009, p. 27)

Os itens acima citados foram destacados por estarem relacionados ao objeto de estudo do presente trabalho, ou seja, a tecnologia educacional utilizada pela Secretaria Estadual de Educação, que será descrita adiante.

A implantação de planos de educação não garante a melhoria da qualidade do ensino. Faz-se necessário, também, ter um sistema de avaliação com mecanismos para acompanhar o cumprimento dos objetivos e das metas estabelecidos como parte das políticas públicas. Como componentes desse sistema de avaliação estão os indicadores de desempenho escolar. Dentre eles o Índice de Desenvolvimento da Educação Básica Ideb -, que aborda dois conceitos para a qualidade da educação: aprovação e média de desempenho dos estudantes. Castro (2009, p. 12) afirma que

o desenho do indicador evita que os sistemas de ensino direcionem suas ações para um dos seus componentes, ou seja, uma escola que reprova sistematicamente, fazendo que muitos alunos abandonem os estudos antes de completar a educação fundamental, não é desejável mesmo que os poucos alunos sobreviventes tenham bom desempenho nas provas nacionais. Também não é desejável uma escola que aprova em massa, sem dar atenção à qualidade da aprendizagem de seus alunos, pois não adianta alcançar taxas elevadas de conclusão dos ensinos fundamental e médio, se os alunos aprendem pouco na escola. (Castro, 2009, p. 12)

A avaliação do desempenho faz parte do monitoramento do ensino e, também, de uma prestação de contas à sociedade.

\section{Breve descrição da gestão escolar}

A Constituição da República Federativa do Brasil (Brasil, 1988) estabelece, em seu artigo 206, os princípios nos quais se baseia o ensino no país. Dentre estes, encontra-se o princípio da gestão democrática, conforme inciso VI do referido artigo.

Para o Ministério da Educação (2004, p. 15), "a gestão democrática implica a efetivação de novos processos de organização e gestão baseados em uma dinâmica que favoreça os processos coletivos e participativos de decisão". Significa que todos os atores do universo escolar têm participação.

Nesse sentido, a Lei de Diretrizes e Bases da Educação Nacional, no artigo 14, determina que "os sistemas de ensino definirão as normas da gestão democrática do ensino público na educação básica" (Brasil, 1996), tendo como princípios a participação dos profissionais da educação na elaboração do projeto pedagógico da escola, bem como a participação das comunidades escolar e local em conselhos escolares.

Trata-se de uma prática complexa, já que envolve diversos indivíduos com diversos interesses e anseios. No entanto, há um consenso, tanto na busca pela melhoria da qualidade do ensino, quanto ao respeito e o aprendizado de um processo democrático 
mais amplo. Para Lück (2006, p. 41) "a gestão democrática ocorre na medida em que as práticas escolares sejam orientadas por filosofia, valores, princípios e ideias consistentes, presente na mente e no coração das pessoas, determinando seu modo de ser e de fazer."

\section{Tecnologia educacional nas escolas estaduais}

A tecnologia foi inserida nas escolas, primeiro nas secretarias, priorizando as atividades administrativas. Depois nos laboratórios de informática, visando promover o uso pedagógico. Atualmente é praticamente impossível separar a educação da tecnologia, já que ela está presente desde a elaboração das atividades pedagógicas até a gestão escolar.

A Secretaria de Estado de Educação implantou um sistema de gestão escolar, o Conexão Educação, com o objetivo de aperfeiçoar processos, permitindo que diretores, professores e funcionários das unidades escolares tenham mais tempo disponível para a garantia de uma educação de melhor qualidade.

Conexão Educação é o sistema de gestão utilizado nas escolas públicas do Estado do Rio de Janeiro desde 2010. Trata-se de um sistema de integração escolar que visa a garantir uma gestão escolar eficiente, ágil e estratégica, reduzir a evasão escolar e melhorar os índices de desempenho em sala de aula.

A concepção original do programa era que, por meio de um único cartão eletrônico inteligente, direção da escola, corpo docente e a própria Secretaria de Estado de Educação do Rio de Janeiro poderiam acompanhar o aprendizado de 1,5 milhão de alunos de forma individual e permanente, compartilhando, em tempo real, informações detalhadas sobre toda a rede estadual de ensino.

Cada estudante da rede estadual de ensino receberia um cartão eletrônico inteligente, com foto e dados cadastrais. Por meio deste sistema de integração online as informações acadêmicas do estudante seriam disponibilizadas em rede. Assim, possibilitaria acompanhar seu desempenho, frequência e até a merenda.

A cada início de aula o professor abriria o sistema com senha própria, acessando uma pauta eletrônica com os nomes dos alunos da turma e espaços para anotações diversas. Durante a aula, o professor registraria observações a respeito do desempenho de cada estudante, facilitando a troca de experiências e propiciando um melhor atendimento aos alunos (Seeduc, 2009).

O projeto Conexão Educação, de iniciativa da Secretaria de Estado de Educação do Rio de Janeiro, passou por significativas mudanças, pois o projeto inicial não foi implantado em toda a rede, somente em algumas poucas escolas na capital do Estado, mas não foi adiante.

Atualmente, o foco do sistema de tecnologia educacional Conexão Educação é aperfeiçoar processos, permitindo que diretores, professores e funcionários das unidades escolares tenham mais tempo disponível para a garantia de uma educação de melhor qualidade (Seeduc, 2013). O sistema é composto dos seguintes portais: Conexão Educação Gestão, Docente Online, Aluno Online e Boletim Online.

O portal Conexão Educação Gestão é acessado somente pelos gestores e pelo secretário da unidade escolar. Por esse portal é possível gerenciar toda a vida escolar dos alunos, desde a matrícula até as notas lançadas, resultados, relatórios de frequência, alunos matriculados, alunos desistentes, declarações e também dos professores, como 
alocação no quadro de horários, carga horária, cadastro etc. Desta forma, atente ao item 11 do Plano Estadual de Educação, anteriormente descrito.

O portal Docente Online ou Conexão Professor é voltado para professores e diretores escolares da rede estadual. Nele os professores realizam o lançamento de notas e faltas bimestrais dos alunos, têm conhecimento das últimas notícias da rede estadual, trocam experiências com profissionais de outras escolas, consultam informações sobre eventos e compartilham seus projetos e ideias. Além das áreas de interatividade, como o fórum e as redes sociais, o Conexão Professor possui áreas pedagógicas com objetos de aprendizagem e o currículo mínimo adotado pela Secretaria de Educação (Seeduc, 2013).

Já o portal Aluno Online ou Conexão Aluno é voltado para os discentes, propiciando acesso a informações sobre a rede estadual, sobre gratuidade nos transportes, boletim e contato com outros alunos da rede.

\section{Procedimentos metodológicos}

A presente pesquisa é classificada como exploratória, pois tem como finalidade "proporcionar maior familiaridade com o problema, com vistas a torná-lo mais explícito" (Gil, 2010, p. 27), uma vez que analisa a percepção e as expectativas dos usuários da tecnologia educacional, para gestão escolar, utilizada na rede estadual de ensino no Estado do Rio de Janeiro.

Para o presente trabalho, foram utilizados como procedimentos a pesquisa bibliográfica e o levantamento. O referencial teórico foi elaborado com base em material já publicado, tais como: livros, dissertações, periódicos. Dando continuidade a coleta de dados, foram solicitadas informações a um grupo de usuários do objeto do estudo: 0 sistema de gestão escolar.

A abordagem do problema é de cunho quantitativo que, conforme Richardson (1999, p. 70), "caracteriza-se pelo emprego da quantificação tanto nas modalidades de coleta de informações, quanto no tratamento delas por meio de técnicas estatísticas". Já a abordagem qualitativa "procura reduzir a distância entre a teoria e os dados" (Teixeira, 2011, p.137). Nesse sentido, a presente pesquisa, quanto à abordagem do problema, é classificada como quantitativa e qualitativa, pois além do tratamento estatístico, também, analisa os dados coletados no ambiente escolar.

O objetivo deste trabalho foi identificar a opinião dos usuários da tecnologia educacional, para gestão escolar, utilizada na rede estadual de ensino no Estado do Rio de Janeiro. Desta forma, o universo da pesquisa é composto pelas escolas públicas do estado do Rio de Janeiro. No entanto, este universo foi delimitado, por acessibilidade, para uma escola pública, localizada na cidade de Volta Redonda/RJ. O objeto do estudo foi o sistema de gestão escolar, Conexão Educação, implantado pela Secretaria de Educação do Estado do Rio de Janeiro. A amostra é composta pelos usuários do sistema de gestão escolar, ou seja, são 67 profissionais que fazem parte da equipe administrativa, pedagógica, além dos professores da instituição de ensino citada.

Para a coleta dos dados foi elaborado um questionário com onze perguntas, sendo dez questões com respostas de múltipla escolha e uma questão descritiva. O questionário foi aplicado no período de 4 a 22 de novembro de 2013, nos turnos da manhã e noite, na referida escola pública. Apesar dos esforços para se obter o maior número possível de respostas, nas três semanas de aplicação do questionário, do total de 67 usuários, foram 
obtidos 40 respondentes, sendo a maioria composta de professores atuantes em sala de aula.

No tratamento dos dados foram tabulados os dados e feita a abordagem quantitativa. Em seguida foram analisadas as respostas, divididas em três categorias: 1) perfil do profissional; 2) relevância da utilização da tecnologia em sua atividade profissional; 3) utilização da ferramenta de gestão Conexão Educação nas escolas públicas do Estado do Rio de Janeiro.

\section{Resultados da pesquisa}

Como análise do perfil dos profissionais da unidade escolar, sobre o período de atuação na educação, observou-se que os 40 respondentes podem ser considerados experientes, já que $70 \%$ atuam há mais de 10 anos na em escola.

Esse resultado indica que, ao longo dos anos de trabalho, estes respondentes puderam vivenciar a implantação da tecnologia no ambiente escolar, tanto como ferramenta para melhorar o processo de aprendizagem, quanto de forma indireta pelo acesso da população aos avanços tecnológicos.

Gráfico 1 -

Período de atuação em escola.

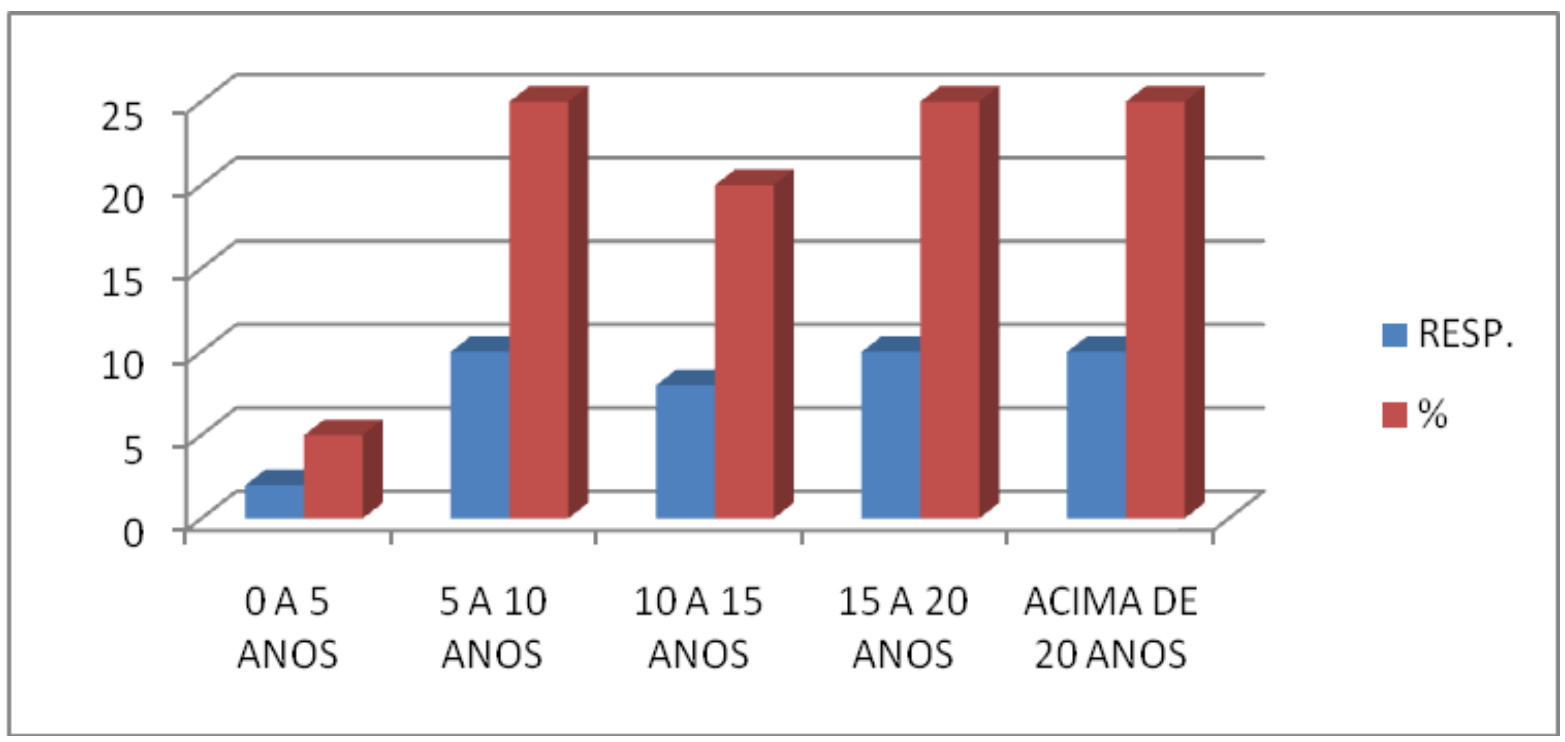

Quanto ao período de atuação em uma escola pública do Estado do Rio de Janeiro, apurou-se que 5\% dos profissionais da pesquisa estão na faixa de 0 a 5 anos, $40 \%$ dos respondentes estão na faixa de atuação de 5 a 10 anos, de 15 a 20 anos trabalhando em escolas públicas estão $20 \%$ dos pesquisados e acima de 20 anos de atuação estão $17,5 \%$ da amostra da pesquisa.

Portanto, pode-se afirmar que a maioria dos profissionais entrevistados, ou seja, $55 \%$ da amostra fazem parte da rede estadual do Rio de Janeiro há mais de 10 anos. No entanto, um número expressivo (45\%) possui menos que 10 anos na referida rede de ensino. Não foi possível a identificação da faixa etária dos respondentes, nem comprovar se esse cenário de proporção se repete em outras unidades de ensino. 
$\mathrm{Na}$ segunda categoria de perguntas foi analisado o papel da tecnologia no desenvolvimento do trabalho na escola. Conforme pode ser observado no gráfico 2, para $42,5 \%$ dos respondentes a tecnologia é de fundamental importância, indispensável na realização do trabalho.

No entanto, $55 \%$ consideram uma ferramenta importante, mas não essencial, pois realizam seu trabalho sem utilizá-la, e apenas 2,5\% não vêem nenhuma importância na utilização da tecnologia, pois consideram que não influencia de forma alguma na realização de seu trabalho.

\section{Gráfico 2}

Papel da tecnologia no desenvolvimento do trabalho escolar.

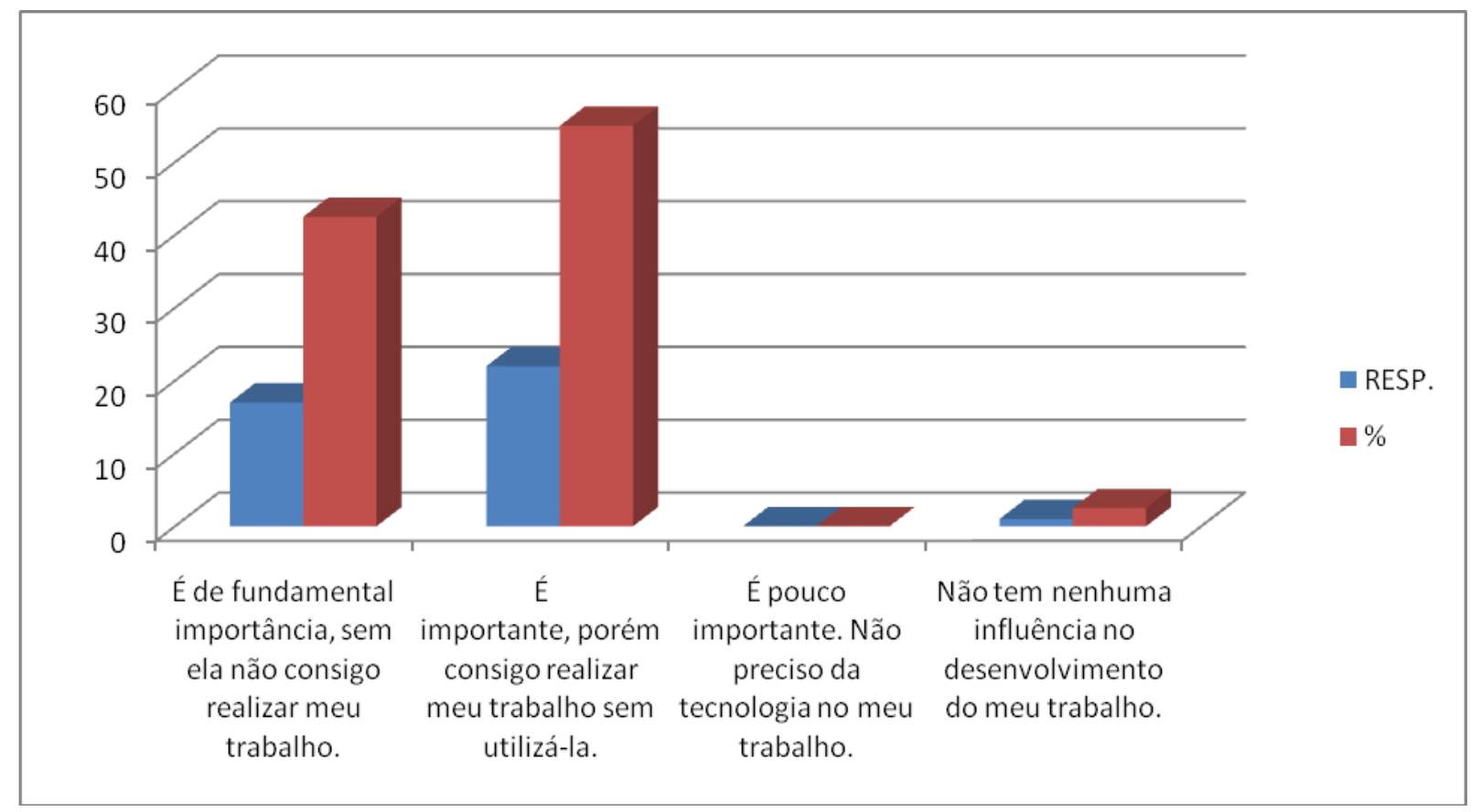

Diante dos resultados apurados pode-se considerar que a tecnologia é utilizada dentro da escola. No entanto, na percepção da maioria dos respondentes ainda não é uma ferramenta essencial no desenvolvimento do trabalho escolar. Tal resultado fortalece a afirmação de Lima (2010) apud Brasão:

para se ter uma ideia, de um conjunto de 400 escolas em treze capitais brasileiras, o número das que dispõem de computadores é elevado: $98 \%$. Só que $72 \%$ dos professores admitem não estar preparados para fazer o uso do equipamento, o que o torna inócuo. Ele acaba se prestando às burocráticas aulas de informáticas, quando não acumula pó nos laboratórios, na ausência de alguém que, pasme-se, consiga manuseá-lo na escola. (Lima, 2010, p. 23)

Contudo, surge a questão: é possível ter qualidade no ensino básico sem tecnologia? Para Silva (2005, p. 63):

a educação do cidadão não pode estar alheia ao novo contexto sócio econômico-tecnológico, cuja característica geral não está mais na 
centralidade da produção fabril ou da mídia de massa, mas na informação digitalizada como nova infra-estrutura básica, como novo modo de produção.

Os governos devem implementar os projetos de inclusão tecnológica visando a capacitar os professores. Estes devem ultrapassar barreiras para resgatar o interesse e a atenção dos alunos, com novas práticas pedagógicas.

A análise das respostas relativas à utilização do sistema de gestão Conexão Educação, nas escolas da rede estadual do Rio de Janeiro, mostrou que o sistema de gerenciamento implantado trouxe benefícios para a educação. Já que $40 \%$ dos profissionais concordam que a ferramenta é útil e $55 \%$ concordam parcialmente que o sistema Conexão Educação tenha utilidade na sua atuação como educador, conforme quadro 1.

Quadro 1 -

Análise do sistema conexão educação.

\begin{tabular}{|l|c|c|c|}
\hline \multicolumn{1}{|c|}{ Conexão Educação } & Concordo & $\begin{array}{c}\text { Concordo } \\
\text { Parcialmente }\end{array}$ & Discordo \\
\hline $\begin{array}{l}\text { Você concorda que a ferramenta de gestão } \\
\text { Conexão Educação seja útil na sua atuação como } \\
\text { professor? }\end{array}$ & $16(40 \%)$ & $22(55 \%)$ & $2(5 \%)$ \\
\hline $\begin{array}{l}\text { Atualmente, quase todas as ações dentro da } \\
\text { escola passam pelo Sistema Conexão Educação, } \\
\text { tanto na parte administrativa como na pedagógica, } \\
\text { existindo assim uma linguagem única entre todas } \\
\text { as escolas da rede. }\end{array}$ & $16(40 \%)$ & $22(55 \%)$ & $2(5 \%)$ \\
\hline $\begin{array}{l}\text { Você acha que as escolas do Estado do Rio de } \\
\text { Janeiro melhoraram a gestão administrativa } \\
\text { (dentro da escola) após a introdução do Sistema } \\
\text { Conexão Educação? }\end{array}$ & $13(32,5 \%)$ & $24(60 \%)$ & $3(7,5 \%)$ \\
\hline
\end{tabular}

Porém, $5 \%$ dos profissionais discordam da eficiência do sistema. Uma das respostas ilustra a insatisfação:

O sistema não contempla o desenvolvimento das atividades em sala de aula, apenas a parte administrativa. Trouxe aumento da carga de trabalho para o professor, pois têm que realizar lançamento de notas tanto no papel (diário) como no sistema. Além disso, atualmente, há uma ênfase em prazos e datas de lançamentos, valorizando-se muito os números e pouco o processo pedagógico.

]

Uma das divisões do sistema de gestão escolar, o portal Conexão Professor, disponibiliza o currículo mínimo a ser trabalhado e algumas sugestões de atividades, 0 que possibilita maior uniformidade entre todas as escolas da rede. Diante disto, $60 \%$ dos respondentes afirmaram que

o sistema possibilita maior agilidade e praticidade no gerenciamento escolar, conferindo às unidades escolares uma visão empresarial, com objetivos e metas mais claros, porém, apresenta falhas e não 
atende a todas as demandas gerenciais, que são peculiares a cada unidade escolar, a cada comunidade escolar, cabendo ao gestor uma visão diferenciada dessas situações.

Com relação à questão da pergunta nove, ou seja, sobre como imaginar a educação do Estado do Rio de Janeiro sem a utilização da ferramenta de gestão Conexão Educação ou de outro sistema tecnológico de gestão, $70 \%$ dos profissionais responderam que não conseguem conceber a gestão escolar dissociada da tecnologia. Porém, enfatizaram que o sistema utilizado pelo Estado do Rio de Janeiro não é bem aproveitado, cabendo aperfeiçoá-lo de modo que tenha uma maior amplitude e eficiência. Ainda segundo relatos dos profissionais, a maioria concorda que a tecnologia é fundamental na gestão escolar. O que conflita com as respostas sobre o uso da tecnologia no seu trabalho.

Essas respostas são confirmadas quando questionados sobre quais os benefícios que a tecnologia traz para a gestão escolar. Dentre os itens citados, o de maior percentual de resposta foi relacionado à gestão das práticas administrativas, conforme percebe-se no quadro 2 a seguir.

Quadro 2 -

Benefícios com a tecnologia.

\begin{tabular}{|l|c|c|}
\hline \multicolumn{1}{|c|}{ Benefícios } & Respostas & $\%$ \\
\hline $\begin{array}{l}\text { Maior rapidez e agilidade no desenvolvimento dos } \\
\text { trabalhos. }\end{array}$ & 13 & 32,5 \\
\hline Proporciona às escolas uma linguagem unânime. & 7 & 17,5 \\
\hline $\begin{array}{l}\text { Possibilita uma melhor visão do todo por parte do } \\
\text { gestor facilitando a tomada de decisão. }\end{array}$ & 15 & 37,5 \\
\hline Facilita a comunicação entre os setores da escola. & 5 & 12,5 \\
\hline Total & 40 & $100 \%$ \\
\hline
\end{tabular}

A última pergunta do questionário aborda a análise do usuário sobre a escola antes e depois da implantação do sistema Conexão Educação. Foi destacado que

o gestor necessita ter uma formação mais completa que envolva, dentre outros aspectos, conhecimento e domínio de ferramentas tecnológicas, que tenha sensibilidade para desenvolver um trabalho inovador, apesar das dificuldades e condições restritivas que muitos enfrentam.

Notou-se que, embora o sistema utilizado na rede estadual do Estado do Rio de Janeiro necessite de aperfeiçoamento, na parte administrativa desempenha papel considerado importante, já que atende o gerenciamento das atividades que envolvem a realização de cálculos, registros de notas, anotação de conteúdos e na secretaria. 0 sistema de registro de alunos é um dos processos que acentua a contribuição da tecnologia, na garantia de uma gestão ágil e integrada, às exigências educacionais, por tratar-se de uma área cada vez mais preocupada com a qualidade dos serviços. 
Ainda conforme os respondentes, a tecnologia no contexto administrativo torna o trabalho mais ágil, diminui a burocracia e evita o desperdício de materiais. Outra resposta merece destaque, pois resume o processo de implantação do sistema:

Antes a escola era muito fragmentada. Cada instituição desenvolvia seu trabalho sem nenhum padrão de eficiência. Era difícil ter ideia do todo e de como as partes precisavam integrar-se para um resultado cada vez mais positivo. O Sistema Conexão Educação ajudou bastante, é inegável. Entretanto é preciso continuar aperfeiçoando-o, em todos os sentidos, principalmente no que se refere ao trabalho direto do professor.

Conforme constatado na pesquisa, o Sistema Conexão Educação apresenta pontos fortes e pontos fracos, que podem ser resumidos no quadro 3, a seguir.

Quadro 3 -

Resumo dos pontos fortes e fracos do Sistema Conexão Educação.

\begin{tabular}{|l|l|}
\hline \multicolumn{1}{|c|}{ Pontos fortes } & \multicolumn{1}{c|}{ Pontos fracos } \\
\hline $\begin{array}{l}\text { Padronização e integração entre as unidades } \\
\text { escolares }\end{array}$ & Aumento da carga de trabalho para o professor \\
\hline $\begin{array}{l}\text { Agilidade na realização das atividades } \\
\text { administrativas }\end{array}$ & $\begin{array}{l}\text { Dificuldade por parte de alguns profissionais em } \\
\text { utilizar as tecnologias }\end{array}$ \\
\hline Melhor visão do todo para o gestor & $\begin{array}{l}\text { Pouca valorização do processo de } \\
\text { aprendizagem }\end{array}$ \\
\hline Maior rapidez na comunicação & Maior foco em números e prazos a cumprir \\
\hline $\begin{array}{l}\text { Maior transparência e eficiência no contexto } \\
\text { administrativo das escolas }\end{array}$ & $\begin{array}{l}\text { Educação do Estado do Rio de Janeiro virou } \\
\text { uma empresa que visa lucros e não a qualidade }\end{array}$ \\
\hline Centralização das informações & $\begin{array}{l}\text { Faltam ferramentas para agilizar o trabalho do } \\
\text { professor }\end{array}$ \\
\hline Facilitador da prática pedagógica & Muita burocracia para pouco resultado \\
\hline
\end{tabular}

\section{Considerações finais}

A base de uma nação é a educação de seu povo. A busca pela qualidade na educação passa por uma gestão eficiente, de forma que se possa atender às necessidades de docentes, discentes e da comunidade na qual a unidade de ensino está inserida. Neste contexto, a tecnologia é uma ferramenta a ser utilizada para agilizar o trabalho e integrar todo o sistema educacional.

Este trabalho teve como objetivo identificar a opinião dos usuários da tecnologia educacional, para gestão escolar, utilizada na rede estadual de ensino no Estado do Rio de Janeiro.

O resultado da pesquisa mostrou que a maioria dos respondentes acredita que o uso da tecnologia não é uma ferramenta essencial ao seu trabalho. Trata-se de uma informação preocupante, pois uma das causas da evasão escolar é a falta de interesse na escola. Aulas ou atividades escolares sem uso da tecnologia estão fora do contexto atual.

Os profissionais da Educação, da rede pública, utilizam a ferramenta tecnológica Conexão Educação. Segundo os resultados da pesquisa essa ferramenta trouxe avanços para a gestão escolar, proporcionando uma mesma linguagem entre as escolas da rede e maior agilidade nos trabalhos burocráticos, já que antes do referido sistema algumas ações tomadas não eram padronizadas, pois cada unidade escolar estipulava um período 
para matrícula e utilizava formulários diferentes para realização do cadastro do aluno. As datas de Conselho de Classe eram marcadas por cada unidade escolar, bem como os quadros de horários das aulas eram feitos manualmente e modificados de acordo com a necessidade. Tudo isso contribuía para que as informações fossem divergentes, fragmentadas, pois cada instituição desenvolvia seu trabalho como se fosse uma organização autônoma, com linguagem e padrões próprios.

O sistema utilizado ainda não contempla todas as necessidades dos profissionais, pois enfatiza as atividades burocráticas e valoriza pouco o processo pedagógico, porém, trouxe maior transparência e eficiência à parte administrativa das escolas, proporcionando ao gestor melhor visão do todo, além de conferir mais interação entre as unidades escolares.

Diante do apurado neste trabalho, o Sistema Conexão Educação apresenta pontos fortes e pontos fracos, como todo sistema. No entanto, cabe, tanto ao governo, quanto a todos os atores do universo escolar, a obrigação de reforçar os pontos fortes e reduzir os pontos fracos, em busca da melhoria da qualidade na educação no estado do Rio de Janeiro.

\section{Referências}

BRASÃO, Mauricio dos Reis. Navegar é preciso: as tics na formação de pedagogos, o olhar dos formadores. Uberaba: Uniube, 2011. 154f. Dissertação (mestrado em Educação). Programa de Mestrado em Educação, Universidade de Uberaba.

BRASIL. Constituição da República Federativa do Brasil de 1988. Disponível em $<$ http://www.planalto.gov.br/ccivil 03/constituicao/constituicao.htm>. Acesso em 14 abr., 2014.

BRASIL. Lei n. 9.394, de 20/12/1996. Estabelece as diretrizes e bases para educação nacional. Disponível em <http://www.planalto.gov.br/ccivil 03/leis/l9394.htm>. Acesso em 14 abr., 2014.

CASTRO, Maria Helena Guimarães de. Sistemas de avaliação da educação no Brasil: avanços e novos desafios. Revista São Paulo em Perspectiva, São Paulo, v. 23, n. 1, 2009 , p. 5-18. Disponível em <http://www.seade.gov.br/produtos/spp/v23n01/ v23n01 01.pdf>. Acesso em 14 abr., 2014.

GIL, Antonio Carlos. Como elaborar projetos de pesquisa. São Paulo: Atlas, 2010.

INEP. Índice de Desenvolvimento da Educação Básica. Disponível em $<$ http://portal.inep.gov.br/web/portal-ideb >. Acesso em 15 abr., 2014.

LIMA, Roberta de Abreu. Quando a aula chega à rede. Revista Veja, 15 set., 2010. Seção Educação, edição 2182, ano 43, n. 37, p. 124-126.

LÜCK, Heloísa. A gestão participativa na escola. Petrópolis: Vozes, 2006.

MEC. Programa nacional de fortalecimento dos conselhos escolares. Conselho escolar, gestão democrática da educação e escolha do diretor. Caderno 5, p. 15. Brasília, 2004. Disponível em <http://portal.mec.gov.br/seb/arquivos/pdf/Consescol/ce cad5. pdf>. Acesso em 16 abr., 2014.

RAUPP, Fabiano Maury; BEUREN, Ilse Maria. Metodologia da pesquisa aplicável às ciências sociais. In: BEUREN, Ilse Maria (org.). Como elaborar trabalhos monográficos em contabilidade: teoria e prática. São Paulo: Atlas, 2006, p. 76-97. 
RICHARDSON, Roberto Jarry. Pesquisa social: métodos e técnicas. São Paulo, Atlas, 1999.

RIO DE JANEIRO. Lei n. 5.597/2009. Aprova o plano estadual de educação. Disponível em <http://download.ri.gov.br/documentos/10112/448712/DLFE31621.pdf/planoEstadual deeducacao.pdf>. Acesso em 15 abr., 2014.

RIO DE JANEIRO. Secretaria de Estado de Educação: conexão educação. Disponível em $<$ www.educacao.ri.gov.br>. Acesso em 26 nov., 2013.

SILVA, Marco. Internet na escola e inclusão. In: ALMEIDA, Maria Elizabeth B. de; MORAN, José Manuel. Integração das tecnologias na educação: salto para o futuro. Brasília: MEC-Seed, 2005. Disponível em <http://portal.mec.gov.br/seed/arquivos/ pdf/2sf.pdf $>$. Acesso em 26 nov., 2013, p. 62-68.

TEIXEIRA, Elizabeth. As três metodologias: acadêmica, da ciência e da pesquisa. Petrópolis: Vozes, 2011.

Lucia Helena Esteves Pereira é secretária escolar no C. E. Nossa Srä do Amparo/RJ. Graduada em Matemática pela Fundação Educacional Rosemar Pimentel, pósgraduada em Psicopedagogia Clínica e Institucional pelo Centro Universitário de Volta Redonda. Professora das disciplinas Matemática e Física no Ensino Fundamental e Médio e da Educação Especial na rede pública.

Endereço: Rua Cinco, 59 - 27283-125 - Volta Redonda - RJ - Brasil.

E-mail: esteves271@ig.com.br.

Isabel Cabral é professora de Contabilidade da Universidade Federal Fluminense em Volta Redonda/RJ. Mestre em Ciências Contábeis pela UFRJ. Professora das disciplinas Contabilidade Internacional, Elaboração das Demonstrações Contábeis. Endereço: Rua Desembargador Ellis Hermydio Figueira, 783 - 27213-415 - Volta Redonda - RJ - Brasil.

E-mail: i.cabral@uol.com.br.

Recebido em 12 de outubro de 2014.

Aceito em 9 de novembro de 2014. 